\title{
Treatment of distal radius metaphyseal fractures in children: a case report and literature review
}

\author{
Firth GB ${ }^{1}$, Robertson AJF² \\ MBBCh(Wits), FCS (Orth), MMed (Orth)(Wits), Orthopaedic Surgeon, Chris Hani Baragwanath Academic Hospital \\ MBBCh(Wits), MMed (Orth)(Wits), Orthopaedic Surgeon, Charlotte Maxeke Johannesburg Academic Hospital
}

Corresponding author: Dr Greg Firth, University of the Witwatersrand, Department of Orthopaedics, 7 York Road, Parktown, 2196; Tel: 011717 2538; Email: greg.firth@gmail.com

\begin{abstract}
Background: The management of displaced distal metaphyseal radius fractures in children is controversial - specifically the prevention of redisplacement. The aim of this article is to establish the indications for the use of Kirschner wires (K-wires) in the management of distal radius fractures in children by reviewing the current literature. The objectives were to establish the remodelling potential in children, factors associated with redisplacement, indications for using K-wires and potential complications of K-wires in distal radius fractures.

Methods and results: A 7-year-old boy with a displaced distal radius fracture was taken to theatre for manipulation and percutaneous fixation with K-wires and subsequently developed a chronic osteomyelitis secondary to the K-wire insertion.

Conclusion: Children under 10 years of age have excellent remodelling potential. The most important risk factors for redisplacement are complete initial displacement, non-anatomic reduction and poor plaster technique. In light of a complication rate of up to $17 \%$, selective use of K-wire fixation in uncomplicated closed fractures should only be considered in children over the age of 10 years in fractures with complete displacement where anatomical reduction cannot be achieved.
\end{abstract}

Level of evidence: Level 5

Key words: distal radius metaphyseal fracture, children, K-wire fixation, remodelling potential

Citation: Firth GB, Robertson AJF. Treatment of distal radius metaphyseal fractures in children: a case report and literature review. SA Orthop J 2017;16(4):59-63. http://dx.doi.org/10.17159/2309-8309/2017/v16n4a10

Editor: Prof Anton Schepers, University of the Witwatersrand

Received: November 2016 Accepted: February 2017 Published: November 2017

Copyright: @ 2017 Firth GB, Robertson AJF. This is an open-access article distributed under the terms of the Creative Commons Attribution Licence, which permits unrestricted use, distribution and reproduction in any medium, provided the original author and source are credited.

Funding: No funding was received.

Conflict of interest: No conflicts of interest are present for either author.

\section{Introduction}

Distal radius fractures are among the most common fractures in children. For displaced distal radius metaphyseal fractures, the vast majority can be treated with manipulation and casting alone. ${ }^{1}$ In recent times the use of $\mathrm{K}$-wire fixation after reduction of these fractures is more common. ${ }^{2}$ Helenius et al. reported a $182 \%$ increase in operative management between 1997 and 2006 in children's fractures. ${ }^{2}$ Complications of this fracture and its treatment include acute compartment syndrome, carpal tunnel syndrome, necrotising fasciitis, nerve injuries, osteomyelitis and malunion. ${ }^{3-6}$ The purpose of this study is to highlight important factors related to treatment decisions of distal radius fractures in children and to make recommendations based on the literature reviewed. These areas will include: 1) the remodelling potential of distal radius metaphyseal fractures; 2) factors associated with redisplacement of these fractures; 3 ) indications for using a $\mathrm{K}$-wire in paediatric distal radius metaphyseal fractures; and 4) potential complications of treatment using K-wires in these fractures (Figure 1) will be highlighted by means of a case report. 


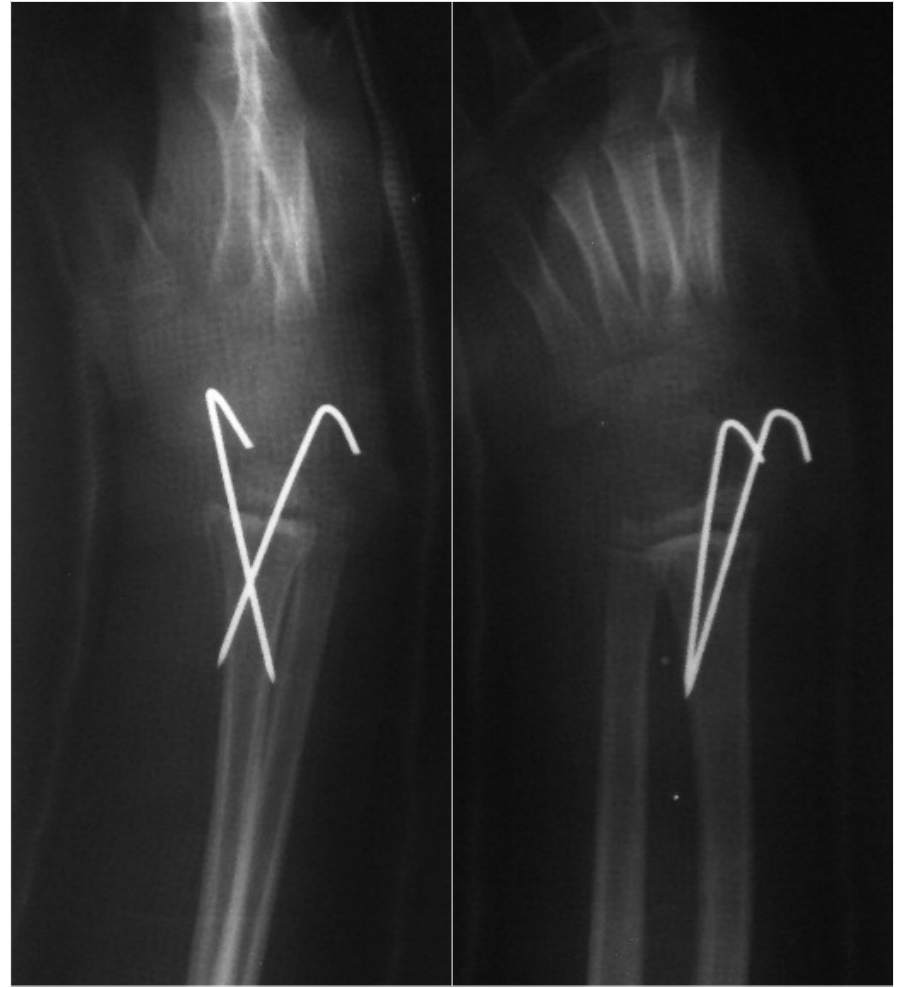

Figure 1A. Radiographs at one month showing reduced distal radius fracture with cross K-wire insertion

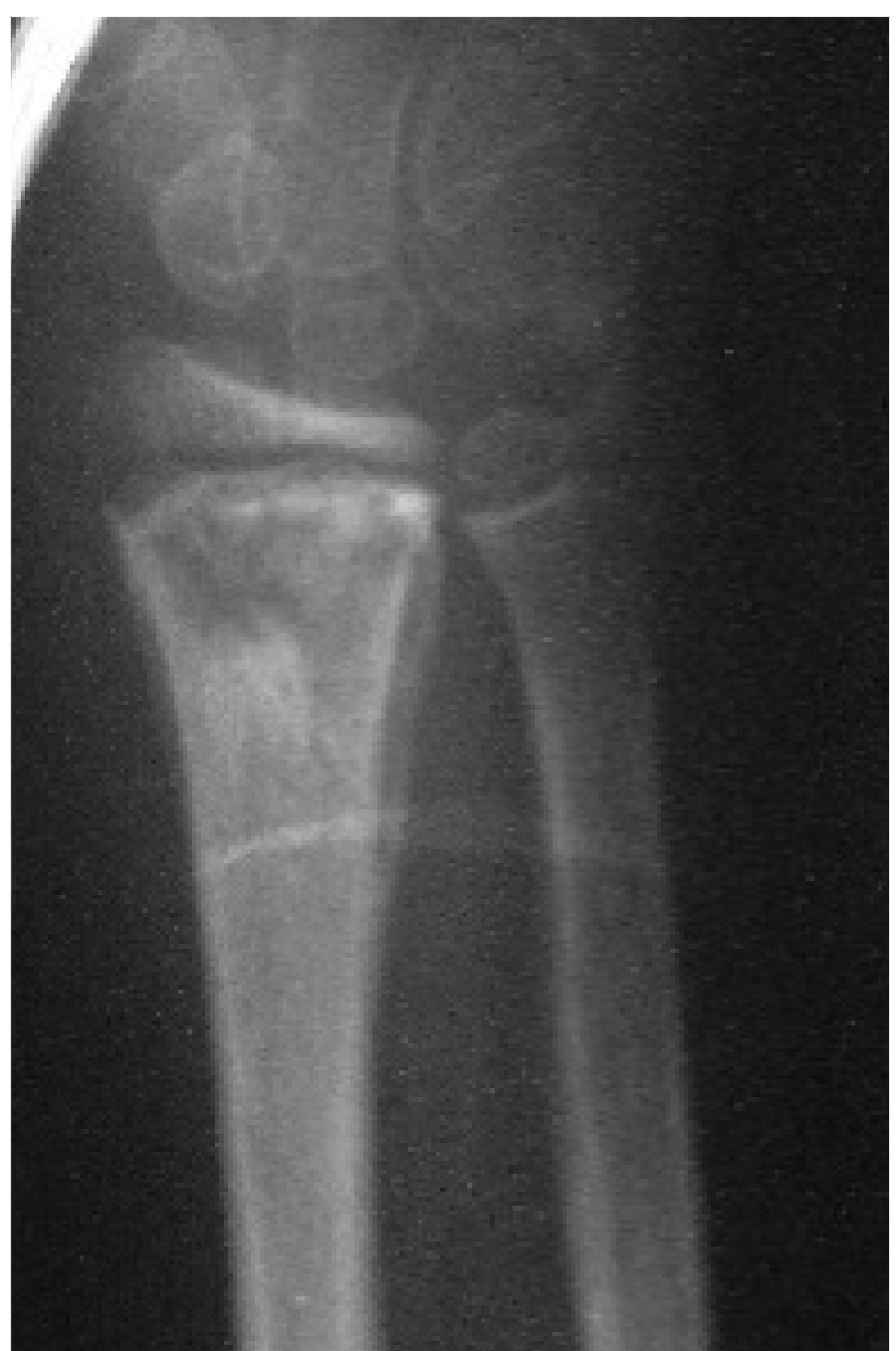

Figure 1B. Radiographs after K-wire removal showing chronic osteomyelitis changes in the metaphysis of the distal radius

\section{Methods and materials}

A review of articles that included children under the age of 17 years with distal radius metaphyseal fractures treated either with manipulation and casting alone or with the addition of K-wires was performed. A search was performed using Medline through Pubmed, EMBASE and the Cochrane Controlled Trials Register. The South African Orthopaedic Journal was also searched online for a local context to the research question. References were reviewed for additional relevant studies. The following search terms were used: Distal radius metaphyseal fracture, child, malunion, K-wire fixation, remodelling. All levels of study, including randomised controlled trials, retrospective controls, observational cohort trials and case reports were reviewed. Treatment method, and clinical and radiological outcomes were recorded. The abstracts of all English articles published between January 1960 and August 2016 were recorded according to the search criteria, saved and studied for eligibility.

Ethics approval was granted from the University's Ethics Board.

\section{Case report}

A 7-year-old boy sustained a closed distal radius fracture and was taken to theatre for manipulation and insertion of cross $\mathrm{K}$-wires (Figure 1A). He was placed in a below-elbow cast and was seen again in the clinic a month after the surgery. At this time, the wound was infected. The child was taken to theatre for a total of three debridements and given cloxacillin as per protocol for chronic osteomyelitis. Eventually the infection settled with closure of the sinus. The X-rays showed changes in keeping with a healing osteitis (Figure 1B). This case highlights the potential complications of K-wire insertion, especially in children under the age of 10 years where there is a large remodelling potential.

\section{Discussion}

\section{Fracture remodelling}

Distal radius fractures in children account for up to $45 \%$ of all paediatric fractures. They usually occur in older children and the thick periosteum helps with reduction and infers inherent stability. The distal radius accounts for $80 \%$ of forearm growth and $40 \%$ of upper extremity growth. Given its contribution to growth there is tremendous remodelling potential for these fractures in children. ${ }^{3}$

Friberg established that the epiphyseal plate changes direction of growth after malunion, with a mean correction per month of 0.9 degrees in the sagittal plane and 0.8 degrees in the coronal plane. The rate of correction was higher in cases with larger primary angulations with an exponential dependence. ${ }^{7}$ The importance of the differential growth response of a physis (i.e. the Heuter-Volkman law) was supported by Wallace et al. ${ }^{8}$ The majority of fracture remodelling in their series of femur fractures in children occurred not only at the fracture site but also at the proximal and distal physes. ${ }^{8}$ Johari et al. confirmed that in the distal radius, more remodelling takes place in the volar dorsal compared to the radio ulna plane. ${ }^{9}$

Fuller et al. reported that children under the age of 5 years with a distal radius fracture malunion over 20 degrees remodelled completely. Only $50 \%$ of children between 6 and 10 years of age remodelled completely and no children between 11 and 14 years of age remodelled completely at final follow-up. However, all of these older patients had a full range of movement at final follow-up. ${ }^{10}$

Roberts stated that there was no relationship between residual radiographic dorsal angulation and pronation/supination in children under the age of 6 years. This was in contrast to older children (range 6-15 years) where almost $50 \%$ of patients had a loss of pronation/supination with more than 15 degrees of malunion. ${ }^{11}$ 
Table I: Remodelling potential of malunited distal radius fractures

\begin{tabular}{|l|c|c|c|c|}
\hline Author & $\begin{array}{c}\text { Age } \\
\text { (years) }\end{array}$ & $\begin{array}{c}\text { Remodelling } \\
\text { time (months) }\end{array}$ & $\begin{array}{c}\text { Initial dorsal } \\
\text { angulation }\end{array}$ & $\begin{array}{c}\text { Final dorsal } \\
\text { angulation }\end{array}$ \\
\hline Jeroense et al. ${ }^{12}$ & 9.1 & 9 & $24^{\circ}$ & $8^{\circ}$ \\
\hline Ghandi et al. ${ }^{13}$ & 7.7 & 35 & $26^{\circ}$ & $5^{\circ}$ \\
\hline
\end{tabular}

In a recent retrospective study by Jeroense et al. the remodelling potential of 33 children with a mean age of 9 years (range 3-14 years) with a distal radius fracture and malunion over 15 degrees was presented. ${ }^{12}$ They confirmed the findings of Friberg et al. ${ }^{7}$ and found that the rate of remodelling decreased exponentially over time. The mean initial remodelling speed was 2.5 degrees per month but decreased exponentially over the 30-month time period. The rate of remodelling was not found to be related to the age of the patient at time of fracture. ${ }^{12}$ Gandhi et al. showed that with longer follow-up (over five years), complete remodelling was possible in distal radius fractures. ${ }^{13}$ Van der Sluijs et al. ${ }^{4}$ recently reviewed the findings of Jeroense et al. $^{12}$ and Ghandi et $a{ }^{13}{ }^{13}$ and postulated a model that described remodelling of the distal radius as an exponential function with starting speed dependent on the initial angulation. Table I illustrates these results.

In summary, there is a tremendous remodelling potential of displaced distal radius fractures in children. Important considerations are the age of the child and amount of initial angulation which dictates the speed of remodelling. Radiological malunion does not always correlate with loss of function.

\section{Factors associated with redisplacement}

A large number of studies have also explored the risks for redisplacement of distal radius fractures in children. The many risk factors that have been identified and studied are summarised in Table II.

It is evident from Table // that there are many possible risk factors for redisplacement. Hang et al. concluded that complete displacement, ipsilateral ulna fracture, failure to achieve a perfect reduction and poor plaster moulding were the main factors associated with redisplacement ${ }^{14}$ whereas Mazzini et al. found the three-point index, a measure of plaster moulding, to be the most useful parameter in predicting redisplacement in 161 children with a mean age of 10 years. They also noted that older children were more likely to redisplace. ${ }^{15}$ Fenton et al. found that younger patients, initial radial translation, increased distance of the fracture from the physis and imperfect reduction were the main risk factors for redisplacement in a group of 73 children with a mean age of 10 years. ${ }^{16}$ Marcheix et al. identified poor cast moulding as the only risk factor for redisplacement. ${ }^{17}$ Chivers et al. concluded that the three-point index was not a useful tool in predicting redisplacement of distal radius fractures in children. ${ }^{18}$

Debnath et al. showed that use of the simpler cast index (the inner diameter of the cast on the lateral radiograph divided by the inner diameter of the cast on the anteroposterior radiograph) was a good predictor for redisplacement. ${ }^{19}$ Kamat et al. refined this and found that a cast index of less than 0.8 (in their study 0.7 was optimal) was associated with a much lower redisplacement rate - in their series of 1001 cases, 249 had a cast index over 0.8 and of these there was a redisplacement rate of $26 \%$ compared to $6 \%$ in those with a cast index less than 0.8. ${ }^{20}$

The above indexes are a measure of adequate plaster moulding or three-point moulding as described by Charnley ${ }^{21}$ and propagated by Rang. ${ }^{22}$

The use of either a short- or long-arm cast has not been conclusively shown to decrease the risk of recurrence. A review article was performed by Hendrickx et al. in 2011 which concluded that belowelbow casts were as effective as above elbow casts in the treatment of distal-third radius and ulna fractures in children. ${ }^{23}$ Advocates of the short-arm cast cite low redisplacement rates, fewer days off school and less interference with activities of daily living. ${ }^{24-26}$

In a retrospective review of 155 children with distal radius fractures, McQuinn et al. found that an initial displacement of more than $50 \%$ or a less than perfect reduction, predisposed to redisplacement. They re-emphasised that the cast index was a useful tool to assess cast moulding as an additional factor to assess the risk of displacement. ${ }^{27}$ Complete initial displacement, initial fracture type and success of reduction have recently been found to be the most important risk factors for redisplacement. 28,29

In summary, from Table // it is evident that the most important risk factors for redisplacement in distal radius fractures in children appear to be complete initial displacement, non-anatomic reduction and poor plaster application technique.

Table II: Risk factors for distal radius fracture redisplacement

\begin{tabular}{|c|c|c|c|c|c|c|c|c|c|c|}
\hline \multirow[b]{2}{*}{ Author (ref) } & \multirow[b]{2}{*}{$\begin{array}{l}\text { Level of } \\
\text { evidence }\end{array}$} & \multicolumn{2}{|c|}{ Patient factors } & \multicolumn{4}{|c|}{ Fracture characteristics } & \multicolumn{3}{|c|}{ Treatment factors } \\
\hline & & $\begin{array}{c}\text { Number of } \\
\text { patients }\end{array}$ & $\begin{array}{l}\text { Mean age } \\
\text { of patients } \\
\text { (years) }\end{array}$ & $\begin{array}{c}\text { Complete } \\
\text { displacement }\end{array}$ & $\begin{array}{l}\text { Distance } \\
\text { from physis }\end{array}$ & $\begin{array}{c}\text { Initial } \\
\text { angulation }\end{array}$ & $\begin{array}{c}\text { Ipsilateral } \\
\text { ulna fracture }\end{array}$ & $\begin{array}{l}\text { Anatomic } \\
\text { reduction }\end{array}$ & Moulding & $\begin{array}{c}\text { Short } \\
\text { equivalent } \\
\text { to long arm } \\
\text { cast }\end{array}$ \\
\hline Hang ${ }^{14}$ & III & 48 & $9.8(0-17)$ & $\checkmark$ & - & $x$ & $\checkmark$ & $\checkmark$ & $\checkmark$ & - \\
\hline Pretell Mazzini ${ }^{15}$ & III & 161 & 10.2 & $\checkmark$ & - & - & - & $\checkmark$ & $\checkmark$ & - \\
\hline Fenton $^{16}$ & III & 73 & $10.4(5-16)$ & $\checkmark$ & $\checkmark$ & - & - & $\checkmark$ & - & $\checkmark$ \\
\hline Marcheix ${ }^{17}$ & III & 60 & $9.8(5-15)$ & $x$ & $x$ & $x$ & $x$ & $x$ & $\checkmark$ & - \\
\hline Chivers $^{18}$ & IV & 43 & - & - & - & - & - & - & & - \\
\hline Debnath $^{19}$ & III & 174 & $9.8(2-15)$ & - & - & - & - & - & $\checkmark$ & - \\
\hline Kamat $^{20}$ & III & 109 & $<10$ & - & - & - & - & - & $\checkmark$ & - \\
\hline Hendrick $x^{23}$ & Review & 300 & - & - & - & - & - & - & - & $\checkmark$ \\
\hline Chess $^{24}$ & IV & 761 & - & - & - & - & - & - & - & $\checkmark$ \\
\hline Bohm 25 & IV & 102 & 8.6 & - & - & - & - & - & - & $\checkmark$ \\
\hline Webb ${ }^{26}$ & I & 113 & Check & - & - & - & - & - & $\checkmark$ & $\checkmark$ \\
\hline McQuinn'²7 & $\|$ & 155 & $<15$ & $\checkmark$ & - & - & - & $\checkmark$ & $\checkmark$ & - \\
\hline Asadollahi²8 & $\|$ & 135 & $9.9(3-17)$ & $\checkmark$ & - & $x$ & $x$ & $\checkmark$ & $x$ & - \\
\hline Jordan ${ }^{29}$ & III & 107 & 10 & $\sqrt{ }$ & $x$ & $x$ & $\checkmark$ & $\checkmark$ & $\checkmark$ & - \\
\hline
\end{tabular}

$\checkmark$ Discussed in article and regarded as significant $\quad x$ Discussed in article and regarded as not important $\quad$ - Not discussed in the article 


\section{Manipulation alone vs use of K-wires}

The results of outcomes following various treatment methods are abundant. The main articles from each type of treatment were identified and used in the discussion of this paper.

The excellent remodelling potential of these fractures was emphasised by Do et al. ${ }^{30}$ This was confirmed by Crawford et al. who reviewed 51 children at an average age of 7 years with overriding distal radius fractures with less than one centimetre of overlap or 15 degrees of angulation. These children were treated without reduction in below-elbow casts. All fractures united and had full range of wrist movement at one-year follow-up. They concluded that children under the age of 10 years did not require anatomical reduction to achieve an excellent result and there was the added benefit of cost saving by avoiding a general anaesthetic. ${ }^{31}$ Roth et al. presented a retrospective cohort of 66 children that presented with redisplacement of more than 15 degrees angulation. They concluded that re-manipulation after initial loss of reduction was not necessary in the majority of patients. They all remodelled to near anatomical alignment and they concluded that they would accept angulation up to 30 degrees in children under 10 years of age, 25 degrees in children between 10 and 12 years and 20 degrees in children over 12 years of age. ${ }^{32}$

Some authors advocate the use of K-wires in selected patients. Van Leemput et al. recommended the use of $\mathrm{K}$-wires in unstable distal radius fractures where there was complete initial displacement, ipsilateral ulna fracture and oblique fracture patterns. This was a Level III comparative cohort study of 39 patients. ${ }^{33}$ This was supported by Wendling-Kim et al. ${ }^{34}$ Selective K-wire insertion was confirmed by Jordan et al. who advocated the use of K-wires for patients in whom suboptimal initial reduction was obtained. Optimal reduction was defined as less than $10 \%$ translation or less than five degrees of angulation. In their series $40 \%$ of patients with suboptimal reduction redisplaced. ${ }^{35}$ Bae et al. considered age an important factor when considering the use of a K-wire. They concluded that children over the age of 10 years should be stabilised with a K-wire if there was initial complete displacement or initial angulation over 15 degrees. ${ }^{36} \mathrm{~A}$ subgroup of patients with median nerve neuropathy and distal radius fractures were also shown to benefit from selective use of K-wire treatment. . $^{37}$

There are only two prospective randomised controlled trials which compare closed reduction alone with closed reduction and percutaneous pinning.

The first study reviewed 68 children with completely displaced distal radius fractures at a mean age of 7.9 years \pm 2.7 years. The authors reported that seven out of 33 patients who had an initial manipulation and cast required a second manipulation. A further seven had residual dorsal angulation more than 20 degrees at union - one of these required a corrective osteotomy at six months. None of the 35 children in the K-wire group required a second procedure. Complications in the K-wire group included two prominent scars and one pin migration which necessitated surgical removal of the $\mathrm{K}$-wire. There was no overall clinical difference between the two groups at three-month follow-up. The authors recommended the use of K-wires for completely displaced distal radius fractures in children. ${ }^{38}$

The second study involved 34 older children with a mean age of 12.4 years. The patients all had either complete initial displacement or initial angulation more than 30 degrees. There was no clinical or cost difference between the two groups at 10.5 week follow-up. Seven (39\%) of the children in the manipulation group required repeat manipulation and one had a transient ulnar nerve palsy. In the K-wire group seven children (39\%) had pin-related complications (two superficial infections, two pin migrations under the skin, one tendon irritation and one transient radial nerve palsy) but all resolved with no long-term complications. They could not recommend one treatment method over the other. ${ }^{39}$
Bernthal et al. highlighted the discrepancy in treating these fractures among orthopaedic surgeons and highlighted differences when comparing hand, paediatric and general orthopaedic surgeons. Hand- and paediatric-trained orthopaedic surgeons accepted more angulation than their adult-trained colleagues. ${ }^{40}$

From these studies, we do not advocate the routine use of $\mathrm{K}$-wires after distal radius fracture manipulation, especially in children under 10 years of age, as the remodelling potential is substantial and there is a risk of complications using K-wires.

\section{latrogenic complications of distal radius fractures}

Major complications following distal radius fractures are rare but as seen in Figure $1 B$ they can be devastating and result in chronic osteomyelitis or growth disturbance. Acute complications related to the fracture itself include neurovascular injury, compartment syndrome, infection with open fractures and even necrotising fasciitis. ${ }^{2}$ More long-term complications include malunion resulting in a decreased range of movement but these complications are extremely rare in the light of the remodelling potential described above. , $^{4,7-13}$

Treatment using K-wires is not without its own complications. The major complications associated with K-wires are neurovascular injuries or infection. A study done by Battle et al. of 202 children (27\% wrist and forearm fractures) showed an overall risk of infection following the use of $\mathrm{K}$-wires in all areas of $7.9 \%$ - the overall rate of deep infection involving bone was $2 \% .^{5}$ Tosti et al. in a review of 884 children who had K-wires inserted reported 12 infections - only one was from a distal radius fracture and was associated with a superficial abscess. ${ }^{41}$

Ramoutar et al. reviewed 248 patients who had distal radius fractures which were manipulated and K-wired. There was a $17 \%$ (42 patients) complication rate related to the K-wires. These complications included K-wire migration requiring general anaesthetic to remove the K-wire, wound over-granulation and scarring, wound infection requiring antibiotics, redisplacement requiring revision surgery, ulna neuropraxia and redisplacement. They concluded that clinicians should be careful before considering the use of K-wires after manipulation of distal radius fractures in children. ${ }^{6}$

Another case report highlighted the risk of developing a Brodie's abscess of the distal radius five-and-a-half years later as a result of initial K-wire fixation. ${ }^{42}$ This case highlights the patient in Figure $1 \mathrm{~A}$ and $1 B$ in which a 7-year-old developed chronic osteomyelitis of the distal radius following manipulation and K-wiring.

\section{Conclusions}

Traditional methods of distal radius metaphyseal fracture care have been challenged in the last few years with increasing parental expectations for a perfect reduction and K-wires with an expedient return to activity. However, according to the literature, this is unsupported as distal radius fractures in children have excellent remodelling potential and associated good functional outcomes after reduction with attention to a well-moulded below-elbow plaster cast. As our case illustrates, the use of $\mathrm{K}$-wires is not without potentially significant complications. Absolute indications for stabilisation using percutaneous K-wires are irreducible fractures requiring open reduction, multiple ipsilateral upper limb fractures, open fractures, and those with associated neurovascular compromise. Indiscriminate use of K-wires in all cases should be avoided. However, from this review, selective K-wiring may be considered when there is complete initial displacement of the fracture or when anatomic reduction is not achieved, particularly in older children. 


\section{Compliance with ethics guidelines}

Ethics approval was granted by the University of the Witwatersrand's Ethics Board.

\section{References}

1. Pannu GS, Herman M. Distal radius-ulna fractures in children. Orthop Clin North Am. 2015 Apr;46(2):235-48.

2. Helenius I, Lamberg TS, Kääriäinen S, Impinen A, Pakarinen MP. Operative treatment of fractures in children is increasing. A population-based study from Finland. J Bone Joint Surg Am. 2009 Nov;91(11):2612-16.

3. Flynn JM, Skaggs DL, Waters PM. Rockwood and Wilkins fractures in children. Eighth Edition. LWW; 2014.

4. van der Sluiis JA, Bron JL. Malunion of the distal radius in children: accurate prediction of the expected remodeling. J Child Orthop. 2016 Jun; 10(3):235-40.

5. Battle J, Carmichael KD. Incidence of pin track infections in children's fractures treated with Kirschner wire fixation. J Pediatr Orthop. 2007 Mar;27(2):154-57.

6. Ramoutar DN, Shivji FS, Rodrigues JN, Hunter JB. The outcomes of displaced paediatric distal radius fractures treated with percutaneous Kirschner wire fixation: a review of 248 cases. Eur J Orthop Surg Traumatol. 2015 Apr;25(3):471-76.

7. Friberg KS. Remodelling after distal forearm fractures in children. I. The effect of residual angulation on the spatial orientation of the epiphyseal plates. Acta Orthop Scand. 1979 Oct;50(5):537-46.

8. Wallace ME, Hoffman EB. Remodelling of angular deformity after femoral shaft fractures in children. J Bone Joint Surg Br. 1992 Sep; 74(5):765-69.

9. Johari AN, Sinha M. Remodeling of forearm fractures in children. $J$ Pediatr Orthop B. 1999 Apr;8(2):84-87.

10. Fuller DJ, McCullough CJ. Malunited fractures of the forearm in children. J Bone Joint Surg Br. 1982;64(3):364-67.

11. Roberts JA. Angulation of the radius in children's fractures. J Bone Joint Surg Br. 1986 Nov;68(5):751-54.

12. Jeroense KT, America T, Witbreuk MM, van der Sluijs JA. Malunion of distal radius fractures in children. Acta Orthop. 2015 Apr;86(2):233-37.

13. Gandhi R, Wilson P, Mason Brown J, Macleod W. Spontaneous correction of deformity following fractures of the forearm in children. $\mathrm{Br}$ J Surg 1962; 50: 5-10.

14. Hang JR, Hutchinson AF, Hau RC. Risk factors associated with loss of position after closed reduction of distal radial fractures in children. J Pediatr Orthop. 2011 Jul-Aug;31(5):501-506.

15. Pretell Mazzini J, Beck N, Brewer J, Baldwin K, Sankar W, Flynn J. Distal metaphyseal radius fractures in children following closed reduction and casting: can loss of reduction be predicted? Int Orthop. 2012 Jul;36(7):1435-40.

16. Fenton $P$, Nightingale $P$, Hodson J, Luscombe J. Factors in redisplacement of paediatric distal radius fractures. J Pediatr Orthop B. 2012 Mar;21(2):127-30.

17. Marcheix PS, Peyrou P, Longis B, Moulies D, Fourcade L. Dorsal distal radius fractures in children: role of plaster in redisplacement of these fractures. J Pediatr Orthop B. 2011 Nov;20(6):372-75.

18. Chivers DA, Hilton TL, Dix-Peek SI. An assessment of the three-point index in predicting the redisplacement of distal radial fractures in children. SA Orthopaedic Journal Winter 2013; Vol 12(2):18-22.

19. Debnath UK, Guha AR, Das S. Distal forearm fractures in children: cast index as predictor of re-manipulation. Indian J Orthop 2011;45(4): 341-46.

20. Kamat AS, Pierse N, Devane P, Mutimer J, Horne G. Redefining the cast index: the optimum technique to reduce redisplacement in pediatric distal forearm fractures. J Pediatr Orthop. 2012 Dec; 32(8):787-91.

21. Charnley J. The Closed Treatment of Common Fractures. Edinburgh. Livingstone 1980.

22. Rang M. Fracture care is a game of chess. In: Rang M. Children's Fractures. JB Lippincott Company; 1983:26-36.

23. Hendrickx RP, Campo MM, van Lieshout AP, Struijs PA, van den Bekerom MP. Above- or below-elbow casts for distal third forearm fractures in children? A meta-analysis of the literature. Arch Orthop Trauma Surg. 2011 Dec;131(12):1663-71.

24. Chess DG, Hyndman JC, Leahey JL, Brown DC, Sinclair AM. Short arm plaster cast for distal pediatric forearm fractures. J Pediatr Orthop. 1994 Mar-Apr;14(2):211-13.
25. Bohm ER, Bubbar V, Yong Hing K, Dzus A. Above and below-the-elbow plaster casts for distal forearm fractures in children. A randomized controlled trial. J Bone Joint Surg Am. 2006 Jan;88(1):1-8.

26. Webb GR, Galpin RD, Armstrong DG. Comparison of short and long arm plaster casts for displaced fractures in the distal third of the forearm in children. J Bone Joint Surg 2006;88A:9-17.

27. McQuinn AG, Jaarsma RL. Risk factors for redisplacement of pediatric distal forearm and distal radius fractures. J Pediatr Orthop. 2012 Oct-Nov;32(7):687-92.

28. Asadollahi S, Ooi KS, Hau RC. Distal radial fractures in children: risk factors for redisplacement following closed reduction. J Pediatr Orthop. 2015 Apr-May;35(3):224-28.

29. Jordan RW, Westacott D, Srinivas K, Shyamalan G. Predicting redisplacement after manipulation of paediatric distal radius fractures: the importance of cast moulding. Eur J Orthop Surg Traumatol. 2015 Jul;25(5):841-45

30. Do TT, Strub WM, Foad SL, Mehlman CT, Crawford AH. Reduction versus remodeling in pediatric distal forearm fractures: a preliminary cost analysis. J Pediatr Orthop B. 2003 Mar;12(2):109-15.

31. Crawford SN, Lee LS, Izuka BH. Closed treatment of overriding distal radial fractures without reduction in children. J Bone Joint Surg Am. 2012 Feb 1;94(3):246-52

32. Roth KC, Denk K, Colaris JW, Jaarsma RL. Think twice before remanipulating distal metaphyseal forearm fractures in children. Arch Orthop Trauma Surg. 2014 Dec;134(12):1699-707.

33. Van Leemput W, De Ridder K. Distal metaphyseal radius fractures in children: reduction with or without pinning. Acta Orthop Belg. 2009 Jun;75(3):306-309.

34. Wendling-Keim DS, Wieser B, Dietz HG. Closed reduction and immobilization of displaced distal radial fractures. Method of choice for the treatment of children? Eur J Trauma Emerg Surg. 2015 Aug;41(4):421-28.

35. Jordan RW, Westacott DJ. Displaced paediatric distal radius fractures - when should we use percutaneous wires? Injury. 2012 Jun;43(6): 908-11.

36. Bae DS. Pediatric distal radius and forearm fractures. J Hand Surg Am. 2008 Dec;33(10):1911-23.

37. Waters PM, Kolettis GJ, Schwend R. Acute median neuropathy following physeal fractures of the distal radius. J Pediatr Orthop. 1994 Mar-Apr;14(2):173-77.

38. McLauchlan GJ, Cowan B, Annan IH, Robb JE. Management of completely displaced metaphyseal fractures of the distal radius in children. A prospective, randomised controlled trial. J Bone Joint Surg Br. 2002 Apr;84(3):413-17.

39. Miller BS, Taylor B, Widmann RF, Bae DS, Snyder BD, Waters PM. Cast immobilization versus percutaneous pin fixation of displaced distal radius fractures in children: a prospective, randomized study. $J$ Pediatr Orthop. 2005 Jul-Aug;25(4):490-94.

40. Bernthal NM, Mitchell S, Bales JG, Benhaim P, Silva M. Variation in practice habits in the treatment of pediatric distal radius fractures. J Pediatr Orthop B. 2015 Sep;24(5):400-407.

41. Tosti R, Foroohar A, Pizzutillo PD, Herman MJ. Kirschner wire infections in pediatric orthopaedic surgery. J Pediatr Orthop. 2015 Jan;35(1): 69-73.

42. Rajakulendran K, Picardo NE, El-Daly I, Hussein R. Brodie's abscess following percutaneous fixation of distal radius fracture in a child. Strategies Trauma Limb Reconstr. 2016 Apr;11(1):69-73. 